[Agr, Biol. Chem., Vol. 36, No. 11, p. 1925 1930, 1972]

\title{
Isolation and Structure of Pestalotin, a Gibberellin Synergist from Pestalotia cryptomeriaecola
}

\author{
By Yasuo Kimura and Saburo Tamura \\ Department of Agricultural Chemistry, The University \\ of Tokyo, Bunkyo-ku. Tokyo
}

Received March 22, 1972

Pestalotin, a gibberellin synergist, was isolated from culture broth of a fungal strain, Pestalotia cryptomeriaecola. The structure of the compound has been established as I on the basis of chemical and spectral data.

During the course of our screening search for plant growth regulators with novel activity among microbial metabolites, we noticed the presence of a gibberellin synergist in culture broth of Pestalotia cryptomeriaecola Sawada, which is a fungus pathogenic for the Japanese ceder, Cryptomeria japonica (Linn. fil.) D. Don. Subsequently, we succeeded in isolating the active principle named pestalotin (I) from the broth and preliminarily reported its biological activity ${ }^{1 /}$ as well as its structure. ${ }^{3}$ In this paper we wish to present in detail our experimental results leading to the structure elucidation.

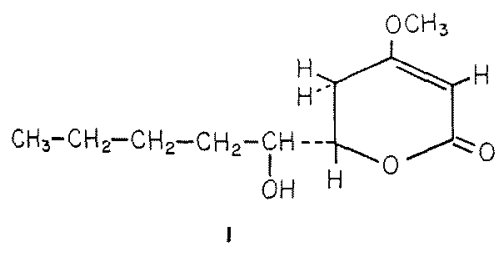

The fungus was grown in shake culture on Czapek-Dox medium for 7 days at $27^{\circ} \mathrm{C}$. Then, the cultured broth was treated by the procedure illustrated in Fig. 1. Acetone was added to the broth, and the mixture was filtered to remove mycelia. The filtrate was evaporated to a small volume and was extracted with ethyl acetate at $\mathrm{pH}$ 3. The

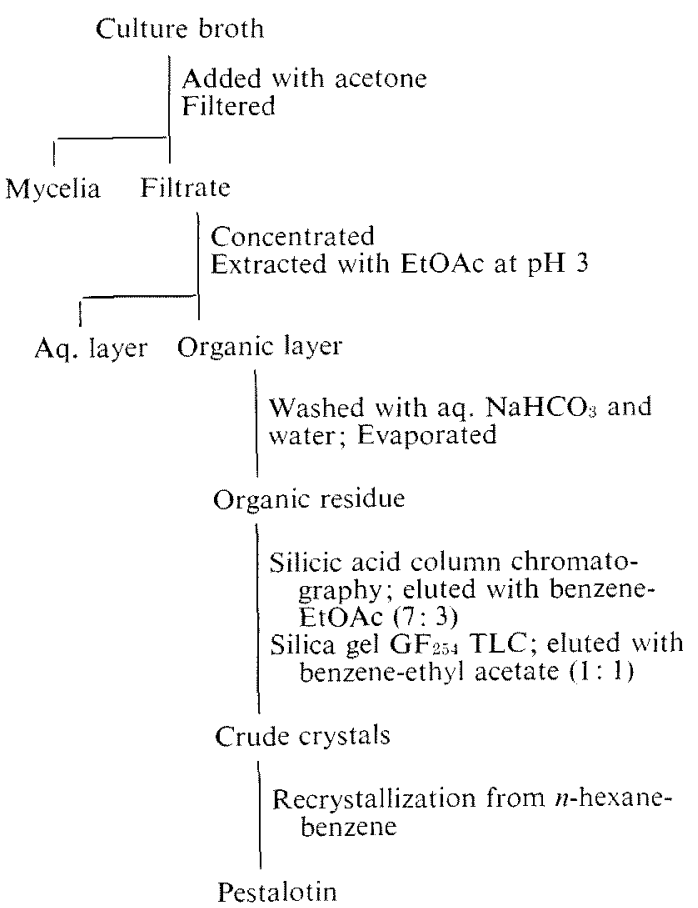

FIG. 1. Isolation Procedure of Pestalotin (1).

extract was shaken successively with dilute sodium bicarbonate solution and water and dried over anhydrous sodium sulfate. After evaporation of the solvent, the neutral residue was chromatographed on a silicic acid column, which was eluted with benzene-ethyl acetate 
increasing stepwise the amount of ethyl acetate. Biological activity was detected in the fraction eluted with benezene containing $30 \%$ ethyl acetate. After evaporation of the solvent, the residue was subjected to thinlayer chromatography (TLC) by use of ethyl acetate-benzene $(1: 1, v / v)$ to give crude crystals of I. Recrystallization from $n$-hexanebenzene afforded colorless crystals melting at $88.0 \sim 88.5^{\circ} \mathrm{C}$.

The molecular formula was established as $\mathrm{C}_{11} \mathrm{H}_{18} \mathrm{O}_{4}$ through elemental analysis and mass spectrometry $\left(\mathrm{M}^{+}\right.$214.1210; Calcd. 214.1205). The IR spectrum of I (Fig. 2) revealed ab- paying the disappearance of the bands at 3480 and $1090 \mathrm{~cm}^{-1}$ observed in $\mathrm{I}$.

In the NMR spectrum of I (Fig. 4), a broad signal at $\delta 2.22$ equivalent to one proton disap. peared by the addition of $\mathrm{D}_{2} \mathrm{O}$, and a oneproton multiplet at $\delta 3.62$ was deshielded to o $5.08(1 \mathrm{H}, \mathrm{m})$ on acetylation. These facts indicate the presence of a secondary hydroxyl group in I, and the above-mentioned oneproton multiplet at $\delta 3.62$ is ascribable to a hydrogen attatched to a carbon atom which bears the hydroxyl. A three-proton singlet at $\delta 3.75$ is attributed to a methoxyl group, and a one-proton doublet at $\delta 5.14(J=2.0$

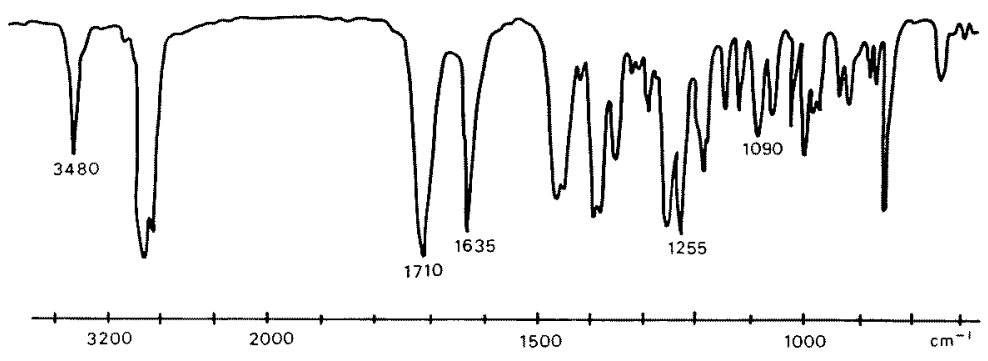

FIG. 2. IR Spectrum of Pestalotin (I) (Nujol).

sorption bands at 3480, $1090(\mathrm{OH}), 1710$ $(\mathrm{C}=\mathrm{O}), 1635(\mathrm{C}-\mathrm{C}), 1255$ and $1025(\mathrm{C}=\mathrm{C}-\mathrm{O}-)$ $\mathrm{cm}^{-1}$ The UV spectrum (Fig. 3) showed an absorption maximum at $233 \mathrm{~nm} \quad(\varepsilon=12,200$ in EtOH). On treatment with acetic anhydride-pyridine, I gave a monoacetate with IR absorption bands at 1745 and $1240 \mathrm{~cm}^{-1}$ characteristic of the ester function, accom-

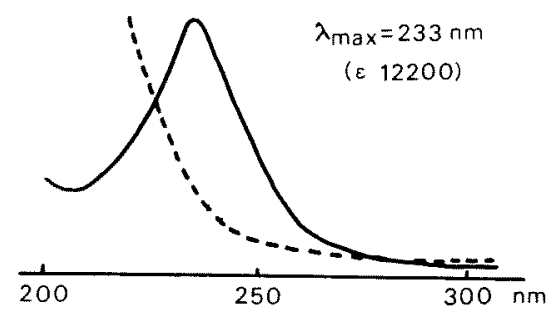

FIG. 3. UV Spectrum of Pestalotin (I) (in EtOH). - neutral or $\mathrm{HCl}$; --. $\mathrm{NaOH}$

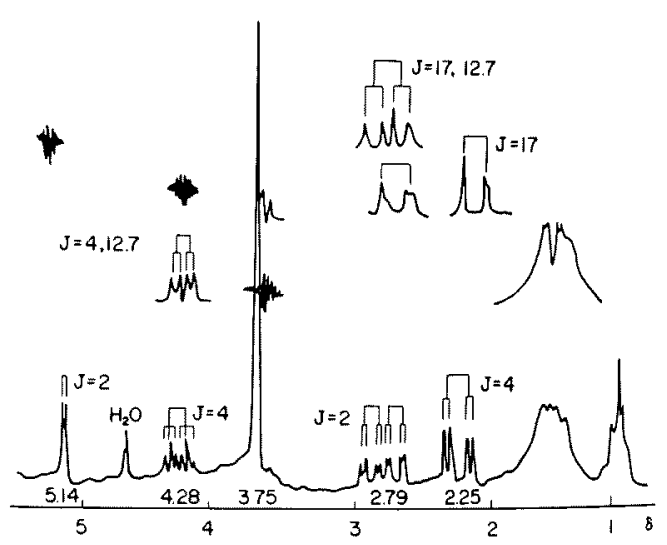

FiG. 4. NMR Spectrum of Pestalotin (I) (in $\mathrm{CDCl}_{3}+$ $\mathrm{D}_{2} \mathrm{O}$ ).

$\mathrm{Hz}$ ) to a trisubstituted double bond. Based on the chemical shift, a one-proton sextet at $\delta 4.28(J=4.0,4.0,12.7 \mathrm{~Hz})$ has been as- 


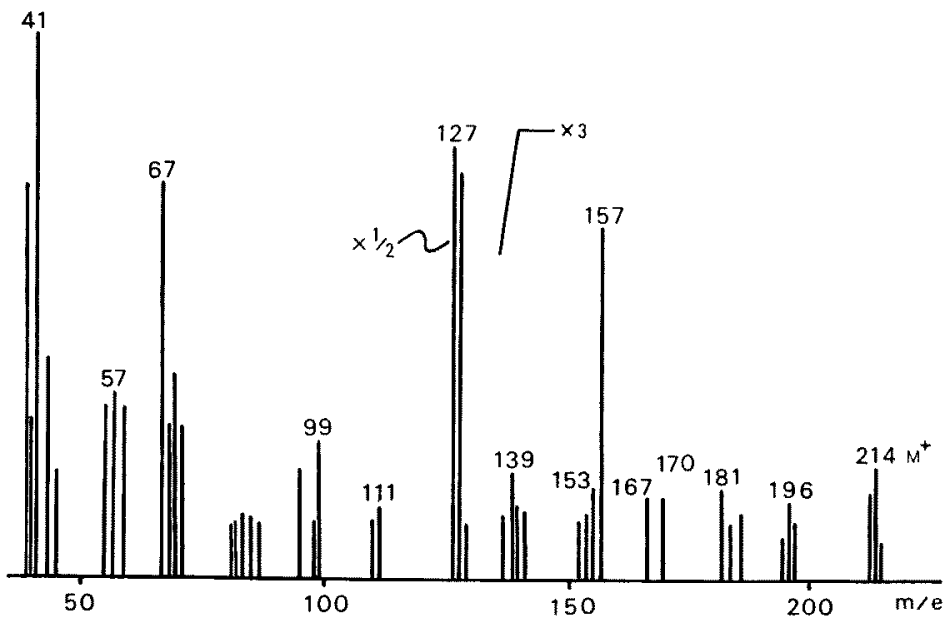

FIG. 5. Mass Spectrum of Pestalotin (I).

signed to a hydrogen located on a carbon atom bearing an oxygen. Irradiation of the signal under consideration revealed couplings with signals at $\delta 2.25(J=4.0,17.0 \mathrm{~Hz}), \delta 2.79$ $(J=2.0,12.7,17.0 \mathrm{~Hz})$ and $\delta 3.62$ mentioned earlier. The large coupling constant $J=17.0$ $\mathrm{Hz}$ indicates geminal relationship of methylene protons. Accordingly, the presence of a partial structure $-\mathrm{CH}_{2}-\mathrm{CH}-\mathrm{CH}(\mathrm{OH})-$ in the O-

molecule of I has been proved.

In the mass spectrum of I (Fig. 5), $\mathrm{M}^{+}-18$ ion peak is observed at $m / e$ 196. Furthermore, fragment ions corresponding to $\mathrm{M}^{+}-\left(\mathrm{H}_{2} \mathrm{O}+\right.$ $\left.\mathrm{CH}_{3}\right), \quad \mathrm{M}^{+}-\left(\mathrm{H}_{2} \mathrm{O}+\mathrm{CH}_{3}+\mathrm{CH}_{2}\right), \quad \mathrm{M}^{+}-\left(\mathrm{CH}_{3}+\right.$ $\left.\mathrm{CH}_{2}+\mathrm{CH}_{2}+\mathrm{CH}_{2}\right), \quad \mathrm{M}^{+}-\left(\mathrm{H}_{2} \mathrm{O}+\mathrm{CH}_{3}+\mathrm{CH}_{2}+\right.$ $\left.\mathrm{CH}_{2}\right)$ and $\mathrm{M}^{+}-\left(\mathrm{H}_{2} \mathrm{O}+\mathrm{CH}_{3}+\mathrm{CH}_{2}+\mathrm{CH}_{2}+\mathrm{CH}_{2}\right)$ were observed at $m / e 181,167,157,153$ and 139. Besides these mass spectral data, NMR signals at $\delta 0.91(3 \mathrm{H}, \mathrm{t}, J=6.3 \mathrm{~Hz})$ and $\delta 1.30 \sim$ $1.60(6 \mathrm{H}$, broad $)$ indicate the presence of a $n$-butyl group. Functions of all the carbon, hydrogen and oxygen atoms constituting I have been fully established as shown in Fig. 6.

Treatment of I with 2,4-dinitrophenylhydrazine revealed no coloration. High inten-

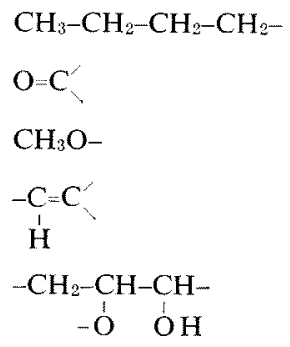

Fig. 6. Functional Groups Constituting Pestalotin (I).

sity of the UV absorption at $233 \mathrm{~nm}(\varepsilon=12,200)$ as well as appearance of IR bands at 1710 and $1635 \mathrm{~cm}^{-1}$ suggests the presence of an $\alpha, \beta$-unsaturated lactone. ${ }^{33} \quad$ Pattern of the UV spectrum is in good accordance with those of 4-methoxy-5,6-dihydro- $\alpha$-pyrone derivatives hitherto reported. ${ }^{4,5}$ Thus, the structure of pestalotin has been assigned as 6-(1'-hydroxypent-1'-yl)-4-methoxy-5,6-dihydro- $\alpha$-pyrone (I).

Validity of the structural assignment was further confirmed by a total synthesis as shown in Fig. 7. Ethyl acetoacetate was condensed with trimethyl orthoformate in the presence of conc. sulfuric acid at room temperature to give ethyl $\beta$-methoxycrotonate (II) ${ }^{6}{ }^{\prime} \quad$ Treat- 


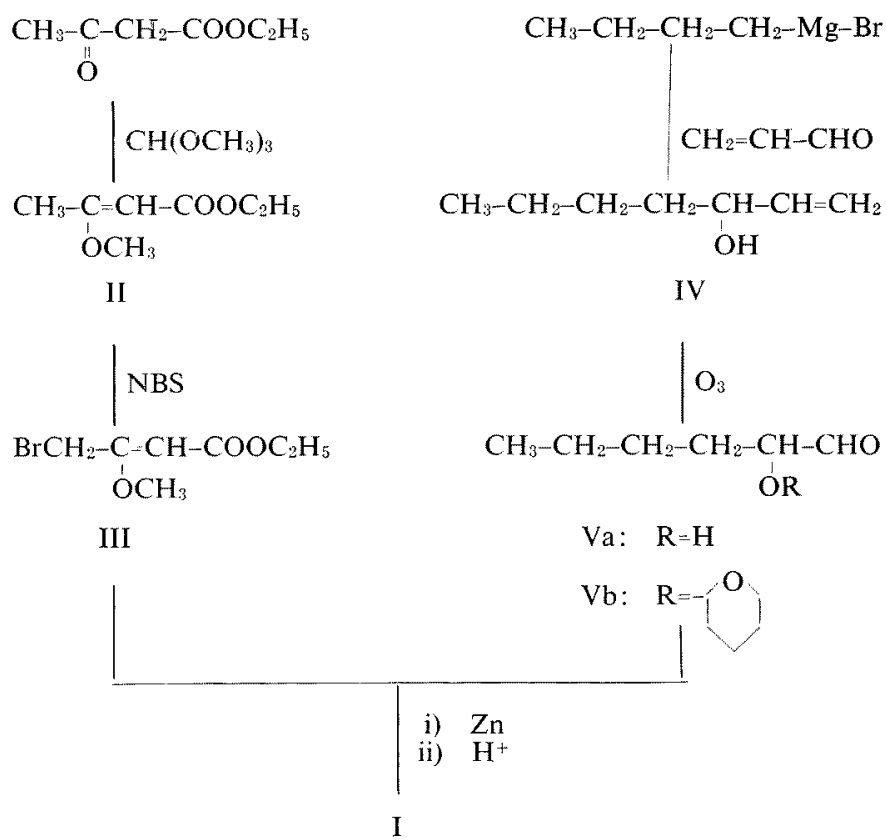

Fig. 7. Synthetic Procedure of Pestalotin (I).

ment of II with $\mathrm{N}$-bromosuccinimide in refluxing carbon tetrachloride yielded $\gamma$-bromo- $\beta$ methoxycrotonate (III) ${ }^{7}{ }^{\prime}$ On the other side, $n$-butylmagnesium bromide was reacted with acrolein to afford 1-helpten-3-ol (IV), which was then subjected to ozonolysis to yield 2hydroxyhexanal (Va). The hydroxyaldehyde was converted into the corresponding pyranyl ether ( $\mathrm{Vb}$ ), and Reformatsky reaction of the ether with III was carried out. The crude product was purified by TLC to give $I$ in a very poor yield. However, comparison of chromatographic behavior and UV and mass spectra showed a complete identity of the natural and synthetic pestalotins.

The CD and ORD curves of natural I possessing two assymmetric carbons is shown in Fig. 8. The negative Cotton effect at $246 \mathrm{~nm}$ ( $J=12.5$ in $\mathrm{EtOH}$ ) in the CD curve suggests that the absolute configuration at $\mathrm{C}-6$ is $s$. However, the stereochemistry of another assymmetric carbon $\mathrm{C}^{-\mathrm{l}^{\prime}}$ remained unsettled.

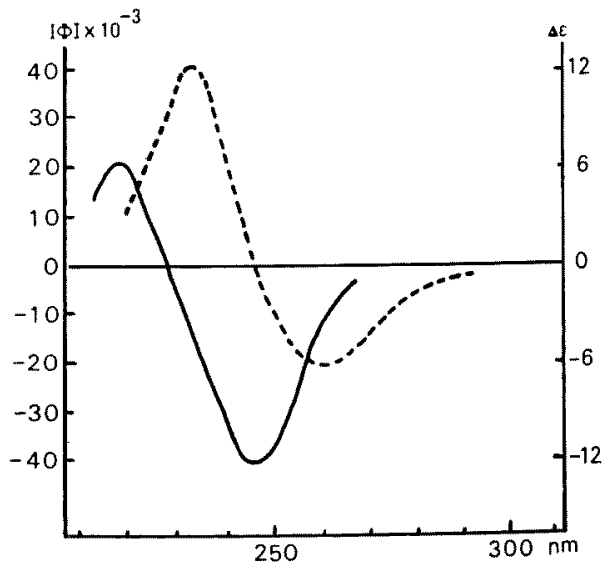

FIG. 8. $\mathrm{CD}$ and ORD Curves of Pestalotin (I) (in $\mathrm{EtOH}$ ).<smiles></smiles>

\section{EXPERIMENTAL}

IR spectra were obtained with a JASCO IR-S spectrometer. NMR spectra were recorded on a JEOL-JNM-4H spectrometer at $100 \mathrm{Mc}$ in $\mathrm{CDCl}_{3}$ solutions. Chemical shifts are expressed in $\delta$ values 
(ppm) with tetramethylsilane as an internal standard. The symbols ' $s$ ', ' $d$ ', ' $t$ ', ' $q$ ' and ' $m$ ' are used to refer to singlet, doublet, triplet, quartet and multiplet, respectively. Mass spectra were measured with a Hitachi RMU-6 at $70 \mathrm{eV}$, and high resolution mass spectra were obtained by a Hitachi RMH-2 with a direct inlet system at $70 \mathrm{eV} . \mathrm{CD}$ and ORD curves were recroded on a JASCO ORD/UV-5 spectrometer by use of ethanol as a solvent.

Isolation of pestalotin. A strain of Pestalotia cryptomeriacecola on an agar slant of potato-sucrose medium was transferred into a $500 \mathrm{ml}$-shaking flask containing $100 \mathrm{ml}$ of Czapek-Dox medium and was grown in shake culture at $27^{\circ} \mathrm{C}$ for 2 days. Twenty $\mathrm{ml}$ of the content in the flask was further transferred into a 5 liters-shaking flask charged with 1.2 liters of the same medium. Cultivation was continued at $27^{\circ} \mathrm{C}$ for 7 days on a rotary shaker.

After addition of an equal volume of acetone, the culture broth was filtered to remove mycelia and was evaporated under reduced pressure. The residual aqueous solution was extracted repeatedly with ethyl acetate at $\mathrm{pH}$ 3. The combined extracts were washed successively with $5 \%$ sodium bicarbonate solution and water. The ethyl acetate was dried over anhydrous sodium sulfate, filtered and evaporated under reduced pressure. The residue $(130 \mathrm{mg})$ was dissolved in benzene and applied to column chromatography using $5 \mathrm{~g}$ of silicic acid. The column was eluted stepwise with $100 \mathrm{ml}$ each of benzene and benzene containing $10,20,30,40$ and $50 \%$ ethyl acetate. The eluate with benzene containing $30 \%$ ethyl acetate afforded $20 \mathrm{mg}$ of crude pestalotin, which was subjected to preparative TLC by use of silica gel $\mathrm{GF}_{25 \text { and }}$ and benzene-ethyl acetate $(1: 1, v / v)$. The zone containing I was extracted with ethyl acetate. The extract was evaporated to dryness under reduced pressure to yield $3 \mathrm{mg}$ of $\mathrm{I}$.

Physico-chemical properties of pestalotin (I). Recrystallization from $n$-hexane-benzene gave $\mathrm{I}$ as colorless plates melting at $88.0 \sim 88.5^{\circ} \mathrm{C} . \mathrm{C}_{11} \mathrm{H}_{18} \mathrm{O}_{4}$. $\mathrm{M}^{+}$214.1210 (Calcd. 214.1205). UV $\lambda_{\max } \mathrm{nm}(\varepsilon)$ : $233\left(12200\right.$ in $95 \%$ EtOH). IR $\nu_{\max }^{\mathrm{Naj} 1} \mathrm{~cm}^{-1}: 3480,1710$, $1635,1255,1090$ and 1025. NMR $\delta: 0.91(3 \mathrm{H}, \mathrm{t}$, $J=6.3 \mathrm{~Hz}), 1.30 \sim 1.60(6 \mathrm{H}$, broad), $2.22(1 \mathrm{H}$, broad), $2.25(1 \mathrm{H}, \mathrm{q}, J=4.0,17.0 \mathrm{~Hz}), 2.79(1 \mathrm{H}, J=2.0,12.7$, $17.0 \mathrm{~Hz}), 3.62(1 \mathrm{H}$, broad), $3.75(3 \mathrm{H}, \mathrm{s}), 4.28(1 \mathrm{H}, \mathrm{m}$, $J=4.0,4.0,12.7 \mathrm{~Hz})$ and $5.14(1 \mathrm{H}, \mathrm{d}, J=2.0 \mathrm{~Hz})$. MS $m / e: 214\left(\mathrm{M}^{+}\right), 196,183,181,170,167,157,153$, 139 and 127 (base peak). I is soluble in most of organic solvents such as benzene, chloroform, ethyl acetate, ether, acetone, and alcohols, but sparingly soluble in $n$-hexane. $\quad R f$ value on TLC being developed with benzene-ethyl acetate $(1: 1, v / v)$ is 0.35 .

Pestalotin monoacetate. I was treated with acetic anhydride-pyridine at room temperature and was allowed to stand overnight. The reaction mixture was poured onto sulfuric acid-ice and extracted with ether. The extract was washed with aqueous sodium bicarbonate successively and was evaporated under reduced pressure. The residual yellow oil was subjected to preparative TLC by use of silica gel GF $F_{254}$ and benzeneethyl acetate $(1: 1, v / v)$. The zone containing the product was extracted with ethyl acetate. Evaporation of the solvent gave the acetate as a colorles oil. $\mathrm{C}_{13} \mathrm{H}_{20} \mathrm{O}_{5}, \mathrm{M}^{+256}$. IR $\nu_{\mathrm{nax}}^{\mathrm{Nujol}} \mathrm{cm}^{-1}: 1745,1710,1635$ and 1240. NMR $\hat{o}: 0.91(3 \mathrm{H}, \mathrm{t}, J=6.3 \mathrm{~Hz}), 1.25 \sim$ $1.50(4 \mathrm{H}$, borad), $1.60 \sim 1.85(2 \mathrm{H}$, broad), $2.14(3 \mathrm{H}, \mathrm{s})$, $2.25(1 \mathrm{H}, \mathrm{q}, J=4.0,17.0 \mathrm{~Hz}), 2.53(1 \mathrm{H}, \mathrm{m}, J=4.0$, $12.7,17.0 \mathrm{~Hz}), 3.74(3 \mathrm{H}, \mathrm{s}), 4.48(1 \mathrm{H}, \mathrm{m}, J=4.0,4.0$, $12.7 \mathrm{~Hz}), 5.08(1 \mathrm{H}, \mathrm{q}, J=4.0,6.0 \mathrm{~Hz})$ and $5.15(1 \mathrm{H}, \mathrm{A}$, $J=2.0 \mathrm{~Hz}$ ).

Ethyl p-methoxy-cis-crotonate (II). This compound was prepared according to the method of Smissman and Voldeng. ${ }^{61}$ Bp $188 \sim 190^{\circ} \mathrm{C}$. MS $m / e: \quad 144\left(\mathrm{M}^{+}\right)$.

Ethyl $\gamma$-bromo- $\beta$-methoxy-cis-crotonate (III). This compound was prepared according to the method of Piantadosi and Skulason." Bp $115^{\circ} \mathrm{C}(18 \mathrm{mmHg})$. MS mle: 224 and $222\left(\mathrm{M}^{+}\right)$.

1-Hepten-3-ol (IV). To the Grignard reagent prepared from $25 \mathrm{~g}$ of $n$-butyl bromide, $4.5 \mathrm{~g}$ of magnesium and a trace amount of iodine in $100 \mathrm{ml}$ of ether was added a solution of $10 \mathrm{~g}$ of acrolein in $50 \mathrm{ml}$ of ether with stirring at a rate to maintain vigorous reflux. The reaction mixture was further refluxed for $2 \mathrm{hr}$ and was poured into a cold $25 \%$ ammonium chloride solution. The ether layer was separated, and the aqueous layer was repeatedly extracted with ether. The combined extracts were washed with water and dried over anhydrous sodium sulfate. After removal of the solvent, the residue was distilled under reduced pressure to give $16 \mathrm{~g}$ of IV. Bp $60 \sim 62^{\circ} \mathrm{C} \quad(17 \mathrm{mmHg})$, IR $\nu_{\max }^{\text {Film }} \mathrm{cm}^{-1}$ : 3420, 1650, 1430, 1000 and 930. NMR o: $0.93(3 \mathrm{H}, \mathrm{t}, J=6.0 \mathrm{~Hz}), 1.20 \sim 1.70(6 \mathrm{H}$, broad $)$, $2.24(1 \mathrm{H}, \mathrm{s}), 4.07(1 \mathrm{H}, \mathrm{q}, J=5.0,14.0 \mathrm{~Hz}), 5.05(1 \mathrm{H}, \mathrm{q}$, $2.0,12.0 \mathrm{~Hz}), 5.20(1 \mathrm{H}, \mathrm{q}, J=2.0,14.0 \mathrm{~Hz})$ and 5.85 $(1 \mathrm{H}, \mathrm{m}, J=5.0,12.0,14.0 \mathrm{~Hz})$. MS $m / e: 114\left(\mathrm{M}^{+}\right)$, 97,81 and 67.

2-Hydroxyhexanal $(\mathrm{V} a)$. A stream of ozonized oxygen was passed through a solution of IV in $30 \mathrm{ml}$ 
of glacial acetic acid. The ozonization was continued until the test of a small portion of the reaction mixture with bromine in the same solvent became negative. Then, $100 \mathrm{ml}$ of ether was added to the reaction mixture, and the ozonide was decomposed with $10 \mathrm{~g}$ of zinc. After filtration, the ether layer was separated and washed successively with ice-cold $10 \%$ potassium carbonate solution and water. The solvent was dried over anhydrous sodium sulfate, filtered and evaporated. The residue was distilled under reduced pressure to give $4.5 \mathrm{~g}$ of $\mathrm{Va}$. $\mathrm{Bp} \quad 60 \sim 68^{\circ} \mathrm{C}(1 \mathrm{mmHg}) . \quad \mathrm{Mp}$ $78.5 \sim 79.5^{\circ} \mathrm{C} . \quad$ IR $\nu_{\mathrm{max}}^{\mathrm{Nujol}} \mathrm{cm}^{-1}: 3470,1725,1090$ and 940. NMR is: $0.93(3 \mathrm{H}, \mathrm{t}, J=6.3 \mathrm{~Hz}), 1.17 \sim 1.75$ ( $6 \mathrm{H}$, broad), 3.60 (1H, broad), 5.19 (1H, broad), and $9.97(1 \mathrm{H}, \mathrm{d}, J=2.5 \mathrm{~Hz})$. MS $m / e: 116\left(\mathrm{M}^{+}\right), 87,78$, 69 , and 57.

2-Pyranoxyhexanal $(V b)$. To a mixture of $2.3 \mathrm{~g}$ of freshly distilled $\mathrm{Va}$ and $2.0 \mathrm{~g}$ of 2,3-dihydropyrane was added $10 \mathrm{mg}$ of $p$-toluenesulfonic acid with stirring. After $2 \mathrm{hr}, 0.5 \mathrm{~g}$ of anhydrous potassium carbonate was added to the reaction mixture, which was then filtered. The filtrate was distilled under reduced pressure to give $2.2 \mathrm{~g}$ of the desired pyranyl ether $(\mathrm{Vb})$. Bp $78^{\circ} \mathrm{C}(5 \mathrm{mmHg}) . \quad$ IR $\nu_{\mathrm{max}}^{\mathrm{Film}} \mathrm{cm}^{-1}: 2940,1738$, $1440,1130,1080,1030$ and 920 . NMR $\delta: 0.92(3 \mathrm{H}$, $\mathrm{t}, J=6.3 \mathrm{~Hz}$ ), $1.25 \sim 1.90$ (12H, broad), 3.50 (1 H, broad), $3.84(2 \mathrm{H}$, broad $), 4.95(1 \mathrm{H}, \mathrm{q}, J=2.5,5.8 \mathrm{~Hz})$ and 9.64 $(1 \mathrm{H}, \mathrm{d}, J=2.0)$. MS m/e: $200\left(\mathrm{M}^{+}\right), 185,170,143$, 129,85 and 67 .

Reformatsky reaction of $V b$ with $I I I$. A mixture of $2.0 \mathrm{~g}$ of $\mathrm{Vb}, 2.3 \mathrm{~g}$ of III and $0.6 \mathrm{~g}$ of activated zinc dust, $16 \mathrm{ml}$ of tetrahydrofuran and $4 \mathrm{ml}$ of ether was heated under reflux for $6 \mathrm{hr}$. The reaction mixture was cooled to room temperature and poured into $100 \mathrm{ml}$ of saturated ammonium chloride solution. After repeated extraction with ethyl acetate, the combined extracts were washed with water, dried over anhydrous sodium sulfate and concentrated under reduced pres sure. The residue was dissolved in methanol contain ing $70 \mathrm{mg}$ of $p$-toluenesulfonic acid and was allowed to stand overnight at room temperature. After neutra. lization with potassium carbonate, the solvent wa removed by vacuum distillation, and the residue was extracted repeatedly with ether. The combined $\mathrm{ex}$. tracts were concentrated to a small volume and sub. jected to preparative TLC on silica gel $\mathrm{GF}_{254}$ by use of benzene-ethyl acetate $(1: 1, v / v)$. The spot of the $R f$ value corresponding to that of I was extracted with ethyl acetate. The residue obtained after evaporation of the solvent showed the following data characteristic of I. UV $\lambda_{\max } \mathrm{nm}$ : 233. MS m/e: $214\left(\mathrm{M}^{+}\right)$ $196,181,167,157,153,139$ and 127 (base peak).

Acknowledgement. The authors wish to thank Mr. K. Aizawa of this Department for the measurements of IR, UV, NMR and mass spectra.

\section{REFERENCES}

1) Y. Kimura, K. Katagiri, T. Inoue and S. Tamura, Agr. Biol. Chem., 35, 1313 (1971).

2) Y. Kimura, K. Katagiri and S. Tamura, Tetrahedron Letters, 3137 (1971).

$3)$ R. Hänsel, H. Rimpler and L. Langhammer, Z. Anal. Chem., 218, 346 (1966).

4) R. Hänsel, L. Langhammer and H. Rimpler, Arch. Pharmaz., 333, 157 (1967).

5) H. Achenbach and H. B. Heubest, J. Chem. Soc., 3259 (1970).

6) E. E. Smissman and A. N. Voldeng, J. Org. Chem., 29, 3161 (1964).

7) C. Piantadosi and V. G. Skulason, J. Pharm Sci., 53, 902 (1964). 